\title{
Prevalence of sensitization to food allergens and challenge proven food allergy in patients visiting allergy centers in Rawalpindi and Islamabad, Pakistan
}

\author{
Muhammad Inam ${ }^{1 *}$, Rubaba Hamid Shafique ${ }^{2}$, Nabila Roohi ${ }^{1}$, Muhammad Irfan², Shahid Abbas ${ }^{3}$ \\ and Muhammad Ismail ${ }^{4}$
}

\begin{abstract}
In this study, we estimated the prevalence of food allergy in the adult allergic patients of Rawalpindi and Islamabad, Pakistan, based on self-report, skin prick test (SPT) and oral food challenge test (OFC). SPT was used for the estimation of sensitization to wheat, egg, milk, beef, chicken, mutton, fish, corn, lentils, rice, soya, peanut and banana. Among 689 patients, $39.19 \%$ showed sensitivity to one or more foods, where, sensitization to wheat (156; $22.6 \%)$ was highest, followed by egg $(148 ; 21.48 \%)$ and milk (138; $20.03 \%)$. Sensitization to various proteins ranged between $15.53-15.97 \%$, while lentils, corn, rice, soya and peanut sensitization was $15.4,16,12.5,12$ and $11.5 \%$ respectively. Only $7.1 \%$ patients were SPT positive for banana allergen. SPT was performed in patients with self-reported food allergy (341/689) and also with no self-reported history of food allergy (348/689). SPT results were positive in $69.8 \%$ of the self-report group, whereas, in the patients with no self-reported food allergy $9.2 \%$ were found sensitized to one or more tested food allergens. 101 patients were recruited for OFC, $61 \%$ of these were confirmed of food allergy. The prevalence of food allergy in the study population was $9 \%$. Food specific OFC results show that wheat allergy is affecting $1.6 \%$ (95\% $\mathrm{Cl} 0.9-2.84 \%$ ) of the total allergy patients, followed by egg allergy $1.31 \%$ (95 \% Cl 0.70-2.47 \%). Furthermore, corn allergy, rice allergy and peanut allergy were $1.02,0.87$ and $0.73 \%$, respectively. In conclusion, wheat allergy is the most prevalent, followed by egg, chicken, beef and fish allergy, respectively.
\end{abstract}

Keywords: Food allergy, Skin Prick Test, Oral food challenge, Food sensitization

\section{Background}

Food allergy is a malfunction of the immune system in response to dietary antigens (Beyer and Teuber 2004). It may involve mechanisms that are IgE-mediated, nonIgE-mediated, or both (Garcia and Lizaso 2011), while all other non-allergic food reactions are categorized as "food intolerance". Like all atopic allergies, food allergy develops in genetically predisposed individuals as a consequence of oral tolerance failure (Sampson 2004). Symptoms of food allergy are as diverse as in other allergies

\footnotetext{
*Correspondence: inammuhammad@hotmail.com

1 Physiology/Endocrinology Lab, Department of Zoology, University of the Punjab, Quaid-i-Azam Campus, Lahore 54590, Pakistan Full list of author information is available at the end of the article
}

involving the oral cavity, skin, respiratory system, circulatory system and gastrointestinal tract. In case of acute food allergy generalized anaphylaxis may also occur (Ballmer-Weber et al. 2007; Kumar et al. 2010; Mackie et al. 2012).

Although there is no substantial scientific evidence, it is estimated that the prevalence of food allergy has increased over the past few decades (van Ree et al. 2015), reaching 3-6\% (exceeding $10 \%$ in some regions), significantly influencing the quality of life and adding to the economic burden of a society (Hadley 2006). Changing dietary habits and availability of all kinds of food products around the world may be a cause of the increase in food allergies. An increase in the prevalence of some food 
allergies like peanut allergy (Sicherer et al. 2003) is not dependent on their increased consumption, but researchers believe that, changes in food production and processing may affect the allergenicity of these foods (Beyer et al. 2001; Chung et al. 2003; Schmitt and Maleki 2003).

The study of epidemiology of food allergies is important in order to elucidate the full gravity of this problem and establish a possible link between increased prevalence of asthma and allergic rhinitis with the rise in food allergy in the past decade (Prescott and Allen 2011). Epidemiological studies and prevalence data on food allergy are either based on self-reported allergic reactions or clinically based allergy tests. Despite reports of increasing prevalence of food allergies and food-induced anaphylaxis in the last decade, there is a need to standardize the methodologies used in various surveys to make a comparison of prevalence studies more objective (van Ree et al. 2015). Age, geographic location, and race/ethnicity are some of the additional factors influencing the prevalence of food allergy in a given population (Hadley 2006). For effective and unbiased determination of the food allergy occurrence, scientists feel the need to overcome misclassifications due to subjective participation in a survey, unavailability of simple diagnostic tests against all types of food allergens, rapidly evolving disease, increasing numbers of potential allergy causing foods, and variable clinical symptoms (Hadley 2006).

A confirmed diagnosis of food allergy necessitates a three dimensional approach. The first step is to identify the possibility of food allergy, based on patients' history (adverse reaction after consumption of a particular food). The second step is the detection of food allergen specific IgE antibodies in the blood through Skin Prick Test (SPT) or immunoassay and finally to establish a clinical relevance of previous procedures with a positive food challenge [(Oral food challenge (OFC) or double-blind, placebo-controlled food challenge (DBPCFC)]. Clinicians usually omit confirmatory food challenges and declare positive food allergy when dealing with patients who have recently suffered from an anaphylactic attack from a particular food and are fulfilling other diagnostic criteria (Steckelbroeck et al. 2008). This procedure helps reduce self-report bias and gives a more objective estimate of food allergy prevalence in a study group (van Ree et al. 2015).

Allergy causing foods contain chemical substances (typically proteins, sometimes with small molecules called haptens) that elicit specific immunologic reactions causing hypersensitivity reactions if eaten uncooked, cooked or sometimes even after they have undergone digestion (Sicherer and Sampson 2010; Waserman and Watson 2011). Out of hundreds of different foods that humans consume, only a small number, account for most of the food allergic reactions. In children approximately $90 \%$ of hypersensitivity reactions are caused by milk, eggs, peanuts, soybeans and wheat, whereas, in adults, fish, shellfish, tree nuts and peanuts account for approximately $85 \%$ of allergic reactions (Krishna 2001). Up to $8 \%$ of children and $2 \%$ of adults in westernized countries suffer from allergic reactions against various foods (Beyer and Teuber 2004). Nearly $4 \%$ of Americans (approximately 12 million) are affected by food allergies, including $3.7 \%$ adults, $6 \%$ children younger than 3 years of age (Sicherer and Sampson 2006). Children with atopic disorders tend to have a higher prevalence of food allergy; about $35 \%$ of children with moderate to severe atopic dermatitis have IgE-mediated food allergy (Eigenann et al. 1998) and about $6 \%$ of children with asthma have food-induced wheezing (Novembre et al. 1988).The National Institute of Allergy and Infectious Disease (NIAID-US) (Boyce et al. 2010) recently concluded that the prevalence of food allergy among all age groups lies between 1-10 \% (Hefle et al. 1996; Sampson et al. 2005).

In the present study, we estimated for the first time, the prevalence of overall food allergy in adult patients visiting various allergy centers in Rawalpindi and Islamabad, Pakistan. The confirmation of allergy was based on the three steps' standard approach. At the same time SPT followed by an OFC test was used to establish the status of sensitization to various food types viz. wheat, egg, milk, beef, chicken, mutton, fish, corn, lentils, rice, soya, peanut and banana.

\section{Methods}

The participants were recruited after an informed consent and approval of the concerned authorities. Patients visiting the various allergy centers were divided into two groups: patients with positive food reaction history and negative food reaction history. Each group underwent Skin Prick Test (SPT) and was further categorized as positive SPT/negative SPT. All positive SPT patients were assessed for their eligibility to undertake the OFC test. The reactions observed were designated as early, late and no reaction according to the time taken for the symptoms to appear (Fig. 1).

\section{Skin Prick Test (SPT)}

Allergen extracts for SPT were purchased from Hollister-Steir (Spokane, WA). Keeping in view the nutritional habit of Pakistani population, 13 food allergens, including milk, beef, chicken, egg, mutton, fish, banana, lentils, peanut, rice, soya corn and wheat were used, crustacean seafood is not consumed as diet in local population therefore, it was not considered for test. Volar aspect of forearm $2-3 \mathrm{~cm}$ from the wrist of the patient was cleaned with ethanol and marked for individual allergens. The 


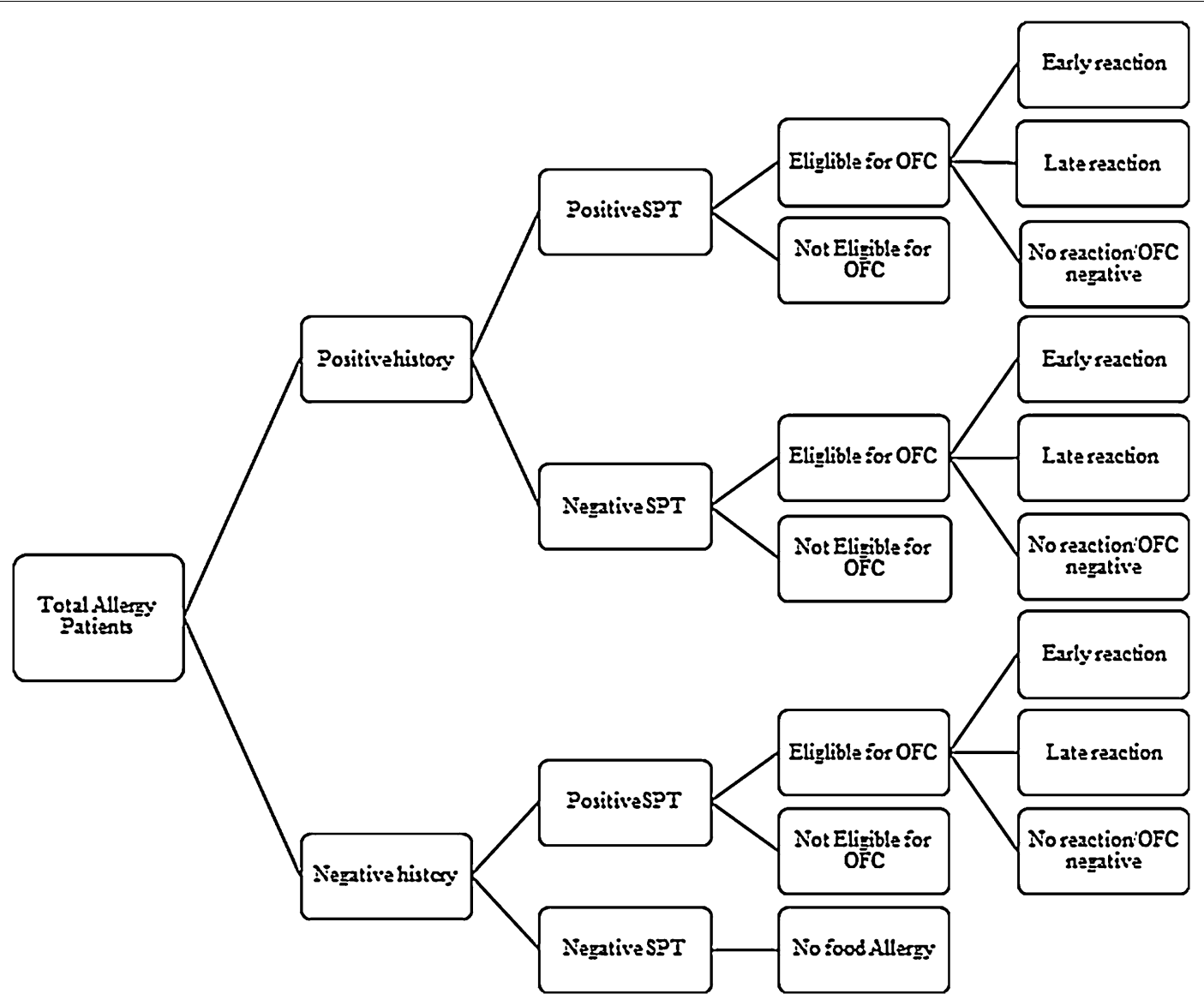

Fig. 1 Methodology used in the present study

distance between skin marks was at least $2 \mathrm{~cm}$ to avoid false positives. Allergen solution was placed beside each mark and the skin was pricked with a sterile lancet. The excess allergen solution was dabbed off. After 20-30 min' appearance of a flare (red inflammation/wheel) was noticed and its size was measured. Wheel size $\geq 3 \mathrm{~mm}$ was considered as positive (Heinzering et al. 2013; Konstantinou et al. 2009).

\section{Diagnostic oral food challenge (OFC)}

Food allergy was diagnosed through oral food challenge at the allergy center under the supervision of a trained physician. Prior to OFC, patients' history was reviewed, each individual was physically examined and baseline of vital signs i.e. spirometry, blood pressure and heart rate etc. were recorded. Patients having recent anaphylaxis, severe asthmatic attack, cardiovascular disease, using beta blockers and carrying pregnancy were eliminated from the OFC group. An informed consent was obtained from each patient who recruited for OFC. Food suspected for allergy was strictly eliminated from the diet of recruited individuals for 2 weeks prior to an OFC and lastly, medications i.e. H1 antihistamines (oral/intranasal), $\mathrm{H} 2$ antihistamine, antidepressants and steroids etc. that may interfere with interpretation were also discontinued $72 \mathrm{~h}$ before the test.

Oral food and fluids were discontinued at least $12 \mathrm{~h}$ prior to OFC. During the OFC procedure, patients were monitored/supervised and regularly re-examined prior to each dose and at first signs of reaction. Spirometry was repeated if respiratory symptoms were observed. Total dose was divided into 6 incremental portions, where every next dose was double of the previous dose e.g. 1, 2, 4, 8 and $16 \mathrm{~g}$ of a solid food or 1, 2, 4, 8, $16 \mathrm{ml}$ of liquid food. In case of suspected severe reaction a much smaller dose was decided. A few randomly selected doses in each test, were disguised to include blinded OFC and reduce any bias from the challenge.

In cases where patients' complained of subjective symptoms (symptoms complained by the patients, i.e. throat or mouth itching, skin itching, or nausea) an observation period was allowed for the development of observable signs of an allergic reaction. However, in case no observable indications developed, OFC was continued. The test 
was considered positive if subjective symptoms followed 3 doses of the test food, with a 30-min interval between each dose (Niggemann 2010; Ito and Urisu 2009). OFC was continued, in spite of the subjective symptoms, until the subject exhibited objective symptoms (i.e. occurrence of flush, local urticaria, or a slight worsening of an underlying eczema). However, in a few cases the challenge was discontinued due to uneasiness or unwillingness of patients to continue the challenge (Niggemann 2010).

The results were considered "positive" until "moderate to severe objective clinical reactions' occurred, such as respiratory, gastrointestinal, skin and cardiovascular symptoms (Ito and Urisu 2009). The challenge was stopped as soon as the observer(s) was/were convinced that a reaction is occurring. All medications that were needed before the challenge and stopped for OFC were administered without delay. OFC was considered negative when the patient tolerated the entire challenge, including the masked and open portions of the OFC. In case of a negative OFC patient was discharged after an observation period of $\geq 2 \mathrm{~h}$. In case of a positive OFC, the patients were retained under observation for $2-4 \mathrm{~h}$ after resolution of symptoms (with or without treatment) depending upon the severity (mild or minimal residual) of the reaction. At the time of discharge from allergy center they were instructed to keep a log of symptoms for at least $48 \mathrm{~h}$ and report back in the clinic in case of late reaction. Patients with a past history of severe reactions, were kept under observation for a long period ( $\geq 6 \mathrm{~h}$ ) even though their symptoms were completely resolved. Skin (oedema, facial flushing, rash or hives) and respiratory symptoms (fall in peak expiratory flow rate or PEFR, severe wheezing) were the most frequent, while a few suffered from gastrointestinal symptoms (vomiting and diarrhea) (Ito and Urisu 2009).

\section{Results}

\section{Sensitization to food allergens}

Overall 689 patients were registered in the study. Their demographic characteristics are shown in Table 1. Two hundred and seventy $(277 ; 39.2 \%)$ patients were sensitized to one or more food allergens, wherein, 266 (98.5\%) patients were poly-sensitized giving positive SPT to more than one tested food allergen. On the other-hand 419 (60.8\%) individuals in the study were SPT positive to other types (i.e. HDM, pollen, dust, etc.) of allergens. Sensitization to wheat $(156 ; 22.6 \%)$ was the most frequent among the food allergens tested followed by sensitization to egg, i.e. 148; 21.5 \% (Table 1; Fig. 2). Sensitization to milk was observed in 138 (20\%) patients, whereas, sensitization to proteins from various meat sources ranged between $15.5-16 \%$. SPT for lentils, corn, rice, soya and peanut was positive in 106 (15.4\%), 110
Table 1 Demographic characteristics of the participants

\begin{tabular}{|c|c|c|c|}
\hline \multicolumn{2}{|c|}{ Characteristics } & \multirow{2}{*}{$\begin{array}{l}\text { Patients N (\%) } \\
n=689\end{array}$} & \multirow[t]{2}{*}{$95 \%(\mathrm{Cl})$} \\
\hline Age & Range (median) & & \\
\hline & 15-73 (36) years & & \\
\hline \multicolumn{4}{|c|}{ Gender } \\
\hline $\mathrm{F}$ & & $302(44)$ & $40.17-47.56$ \\
\hline M & & $387(56)$ & $52.44-59.83$ \\
\hline Sensit & d allergens & $270(39)$ & $35.61-42.89$ \\
\hline \multicolumn{4}{|c|}{ Animal proteins } \\
\hline Milk & & $138(20)$ & $17.2-23.18$ \\
\hline Beef & & $109(16)$ & $13.29-18.73$ \\
\hline Chic & & $110(16)$ & $13.42-18.89$ \\
\hline Egg & & $148(21)$ & $18.58-24.7$ \\
\hline Mut & & $107(16)$ & $13.02-18.42$ \\
\hline Fish & & $107(16)$ & $13.02-18.42$ \\
\hline \multicolumn{4}{|c|}{ Plant foods } \\
\hline Ban & & $49(7)$ & $5.42-9.28$ \\
\hline Lent & & $106(15)$ & $12.88-18.27$ \\
\hline Pear & & $79(12)$ & $9.33-14.10$ \\
\hline Soya & & $83(12)$ & $9.83-14.69$ \\
\hline Rice & & $86(13)$ & $10.22-15.16$ \\
\hline Corr & & $110(16)$ & $13.42-18.89$ \\
\hline Whe & & $156(3)$ & $19.67-25.91$ \\
\hline \multicolumn{4}{|c|}{ Other allergens } \\
\hline $\mathrm{HDN}$ & etc. & $419(61)$ & $57.11-64.39$ \\
\hline \multicolumn{4}{|c|}{ Symptoms } \\
\hline Resk & & $522(76)$ & $72.42-78.81$ \\
\hline Cuta & & $250(36)$ & $32.78-39.94$ \\
\hline OFC $r$ & & $n=101$ & \\
\hline Early & hin 2 h) & $50(50)$ & $39.95-59.09$ \\
\hline Late & 8 h) & $12(12)$ & $6.93-19.63$ \\
\hline $\mathrm{Neg}$ & & $39(39)$ & $29.7-48.36$ \\
\hline \multicolumn{4}{|c|}{ Treatment } \\
\hline Yes & & $265(38)$ & $34.90-42.51$ \\
\hline No & & $424(62)$ & $57.85-65.10$ \\
\hline
\end{tabular}

(16\%), 86 (12.5\%), 83 (12\%) and 79 (11.5\%) patients respectively. Only $49(7.1 \%)$ patients were SPT positive for banana allergen (Fig. 2).

Among 270 food sensitized individuals, animal protein (e.g. milk, beef, chicken, egg, mutton or fish) sensitivity was the most common ( $47 \%$ prevalence) followed by wheat sensitivity (10 \%) (Fig. 3).

\section{OFC based food allergy}

Out of 689 adult patients (age 15-73 years) that visited the allergy clinic, 341 (49.5\%) had self-reported history of food allergy whereas 348 (50.5\%) did not report any adverse food reactions. All patients were screened through SPT to determine food sensitivity. Two hundred 


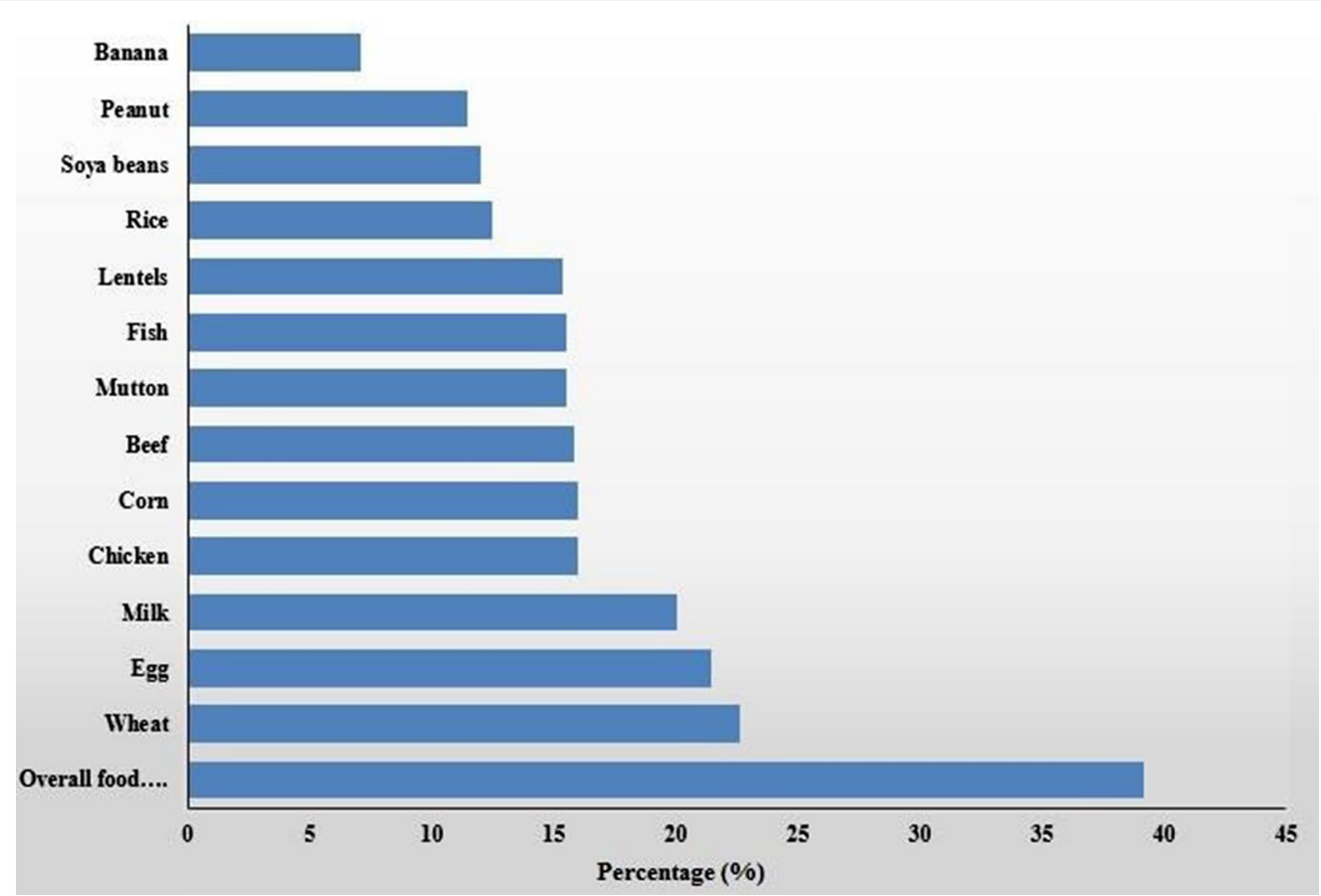

Fig. 2 Sensitization (\%) to various food allergens in the study group $(n=689)$

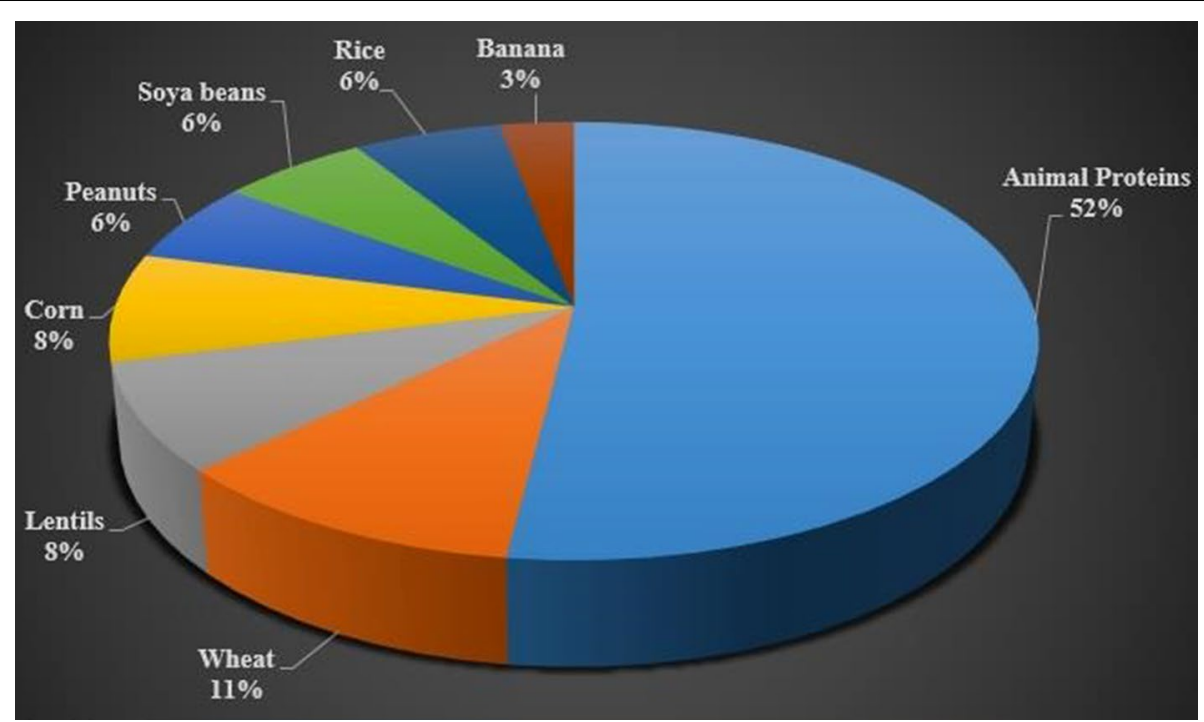

Fig. 3 Distribution of percent sensitization to various food allergens in SPT positive group $(n=270)$

and thirty-eight (238) out of 341 (69.8\%) self-reported allergy patients were SPT positive to 1 or more tested allergens, whereas 103 (30.2 \%) did not show sensitization to any food allergen (Table 2). Among 348 individuals who did not experience any food allergy symptoms, $32(9.2 \%)$ were found sensitized to one or more tested food allergens while $316(90.8 \%)$ presented a negative
SPT. These patients were not included in open OFC and were designated negative for food allergy. Patients from all the remaining groups were assessed for their eligibility to undertake the open OFC test. Sixty-one percent (61\%: $62 / 101)$ of the patients that participated in OFC were diagnosed of food allergy. In the total study population $(n=689)$ the prevalence of food allergy was $9 \%$. 
Table 2 An overview of participation in the oral food challenge (OFC)

\begin{tabular}{lllll}
\hline $\begin{array}{l}\text { Total allergy } \\
\text { patients }(\mathbf{n = 6 8 9 )}\end{array}$ & Patient history (N) & $\begin{array}{l}\text { Skin Prick Test } \\
(\text { SPT) results (N) }\end{array}$ & Eligible for OFC (N) & Not eligible for OFC (N) \\
\hline Positive & 341 & Positive (238) & 54 & $\begin{array}{c}\text { 184 [An (9), SA (98), CVP (34), CP (20) } \\
\text { and R (23)] }\end{array}$ \\
Negative & Negative (103) & 36 & 67 \\
& 348 & Positive (32) & 11 & $21[$ SA (2), CVP (9), CP (3) and R (7)] \\
& & Negative (316) & No food allergy & \\
\hline
\end{tabular}

An anaphylaxis; $S A$ severe asthma; $C V P$ cardiovascular patients/ $\beta$-blocker users; $C P$ carrying pregnancy; $R$ refusal

In the open OFC participating group, 65 (64.3\%) were SPT positive and $36(35.6 \%)$ were SPT negative. 50 $(49.5 \%)$ of the participants showed early reaction and $12(11.9 \%)$ showed a late reaction, whereas 39 (38.6\%) did not show any reaction (Table 3 ). Food specific OFC results show that wheat allergy is most prevalent, affecting at least $1.6 \%$ (95\% CI 0.9-2.84\%) individuals in the total allergy patients, whereas in the OFC trial group the prevalence was $10.99 \%$ (95 \% CI 6.19-18.46\%), followed by the prevalence of egg allergy, that was $1.3 \%$ (95\% CI $0.70-2.47 \%$ ) and $8.9 \%$ (95 \% CI 4.76-16.07\%) in total allergy patients and OFC group respectively (Table 4).

A moderate correlation $(r=0.41)$ was observed between food allergens' sensitized and OFC confirmed allergy groups. But there was no positive linear relationship observed between allergy symptoms, food allergens' sensitized, and OFC confirmed allergy groups.

\section{Discussion}

Among 689 patients suffering from allergy diseases, sensitization to food allergens was found in 270 (39.2\%) at $95 \%$ CI. Previously, only one local study is available reporting SPT data from the National Institute of Health (NIH) Islamabad. The prevalence of food sensitization in this report was estimated (only 2.3-3 \%) in allergy patients against five selected foods (beef, mutton, egg, rice and fish), while worldwide studies reported 32-35 and $41.7 \%$ sensitization to various food allergens in allergy patients from India (Sai et al. 2006) and Hungary (Bakos et al. 2006), respectively are comparable to our findings.
Animal proteins tested for allergy in the target population in our research included milk, beef, mutton, fish, chicken and egg. Global sensitization to beef allergens lies between 2 and 31.8 \% (Orhan et al. 2009; Lessof et al. 1980; Gendeh et al. 2000; Sampson and McCaskill 1985; Burks 1999; Fiocchi et al. 1995) with a mean percentage of $13.5 \%$, which is consistent with findings in the present study (15.82 \%). Allergy patients' group participating in this research showed high percent sensitization to milk allergens (20.03\%). Kumar et al. (2011) in 2011 reported $21.9 \%$ children (6 months to 6 years) with high serum IgE against milk allergens. Most of the studies focusing on milk allergen sensitization using SPT, target various age groups of children. Worldwide SPT data are highly variable, $1 \%$ milk sensitivity was reported from Turkish hospital (Kucukosmanoglu et al. 2008), $1.1 \%$ of random school children in Turkish population (Mustafayev et al. 2013) and $0.1 \%$ in the general population in Germany (Zuberbier et al. 2004). Studies from other countries including USA, China, Australia and Turkey report $10.5,6.5,5.6$ and $18.1 \%$ sensitization to milk in general population, respectively (Orhan et al. 2009; Greenhawt et al. 2009; Hu et al. 2010; Osborne et al. 2011). While in another study from Israel, children with allergy diseases (age 0-2 years) had alarmingly high serum IgE levels (Katz et al. 2010). The study also compared the frequency of occurrence in males and females and found $62 \%$ male and $37.9 \%$ female children sensitized to milk. $15.5 \%$ SPT positive patients to fish allergen were recorded here. Sai (2011) reported $11.2 \%$ sensitization to fish in all age groups in China, whereas most of the other reports

Table 3 Oral food challenge (OFC) test results

\begin{tabular}{|c|c|c|c|c|}
\hline $\begin{array}{l}\text { Total participants } \\
\text { in OFC }(n=101)\end{array}$ & $\begin{array}{l}\text { Skin Prick Test (SPT) } \\
\text { results N (\%) }\end{array}$ & Early reaction $\mathrm{N}(\%)$ & Late reaction $\mathrm{N}(\%)$ & $\begin{array}{l}\text { No reaction } \\
\text { (OFC negative) N (\%) }\end{array}$ \\
\hline Positive & $65(64.3)$ & $50(49.5)$ & $10(9.9)$ & $5(4.9)$ \\
\hline Negative & $36(35.6)$ & Nil & $2(1.9)$ & $34(33.6)$ \\
\hline Total & & $50(49.5)$ & $12(11.8)$ & $39(38.6)$ \\
\hline
\end{tabular}


Table 4 Food type specific OFC test results

\begin{tabular}{|c|c|c|c|c|}
\hline \multirow[t]{2}{*}{ Food type } & \multicolumn{2}{|c|}{ Total patients $n=689$} & \multicolumn{2}{|c|}{$\begin{array}{l}\text { OFC participants } \\
n=101\end{array}$} \\
\hline & N (\%) & $95 \%$ Cl (\%) & $\mathrm{N}(\%)$ & $95 \% \mathrm{Cl}(\%)$ \\
\hline \multicolumn{5}{|c|}{ Animal proteins } \\
\hline Milk & $4(0.58)$ & $0.23-1.48$ & $4(3.96)$ & $1.55-9.74$ \\
\hline Beef & $6(0.87)$ & $0.40-1.89$ & $6(5.94)$ & $2.75-12.36$ \\
\hline Mutton & $2(0.29)$ & $0.08-1.05$ & $2(1.98)$ & $0.54-6.93$ \\
\hline Fish & $5(0.73)$ & $0.31-1.69$ & $5(4.95)$ & $2.13-11.07$ \\
\hline Chicken & $7(1.01)$ & $0.50-2.09$ & $7(6.93)$ & $3.40-13.62$ \\
\hline Egg & $9(1.31)$ & $0.70-2.47$ & $9(8.91)$ & $4.76-16.07$ \\
\hline \multicolumn{5}{|l|}{ Plant foods } \\
\hline Banana & $\mathrm{Nil}$ & Nil & Nil & $\mathrm{Nil}$ \\
\hline Lentils & Nil & Nil & Nil & Nil \\
\hline Peanut & $5(0.73)$ & $0.31-1.69$ & $5(4.95)$ & $2.13-11.07$ \\
\hline Soya beans & $\mathrm{Nil}$ & Nil & Nil & Nil \\
\hline Rice & $6(0.87)$ & $0.40-1.89$ & $6(5.94)$ & $2.75-12.36$ \\
\hline Corn & $7(1.02)$ & $0.50-2.09$ & $7(6.93)$ & $3.40-13.62$ \\
\hline Wheat & $11(1.6)$ & $0.90-2.84$ & $11(10.89)$ & $6.19-18.46$ \\
\hline
\end{tabular}

targeted children, where percentage sensitization to fish allergen was found between $0-2.7 \%$ ( $\mathrm{Hu}$ et al. 2010; Haahtela et al. 1980; Ben-Shoshan et al. 2010; Roberts and Lack 2005; Chen et al. 2011). SPT results for chicken meat showed $16 \%$ sensitization in the allergy patients participating in the present study. Previous studies again show variable results ranging from $6.5 \%$ in $5-14$ years of age group from Italy (Hu 2009) up to $20 \%$ in Madrid, Spain (Caffarelli et al. 2010). Egg allergen sensitization in Pakistani population was $21.5 \%$. A report from an allergy clinic in Boston, USA demonstrated similar results, where $21.4 \%$ of 1104 allergy patients had high levels of serum specific IgE for egg allergen (Kumar et al. 2011).

Peanuts, soya beans and lentils belong to legumes that are consumed commonly in Pakistan. Sensitization to peanuts in the study group was $11.50 \%$. These data closely match with earlier reports from the Netherlands (Añibarro-Bausela et al. 2010) and USA (Kumar et al. 2011) where SPT results revealed 13 and $13.4 \%$ peanut sensitization respectively. A study from the UK found $0.4 \%$ sensitization to peanuts in children below 3 years of age. Most worldwide studies estimated low percentage sensitization to soya beans in the general population, i.e. 0-3.3 \% (Zuberbier et al. 2004; Van Veen et al. 2013; Kristjansson et al. 1999; Ostblom et al. 2008; Emmett et al. 1999). One study from Hungary that carried out SPT in 20-69 years of age group, reported $8.3 \%$ soya bean sensitization (Bakos et al. 2006), these data are comparable to the percentage (12\%) of sensitization to soya beans in the present study. For lentils (pulses) our SPT results showed $15.4 \%$ positive reaction. A previous study from Spain found $12.6 \%$ self-reported allergy to lentils (Dalal et al. 2002), whereas 0.04 and $2 \%$ lentil sensitivity was reported from UK (Emmett et al. 1999) and Europe (Martinez-Gimeno et al. 2000), respectively.

Sensitization to cereals was tested here, using allergens from wheat, rice and corn. Percent sensitization to wheat $(22.6 \%)$ was the highest in the study group. Earlier reports show 0.00-13.9 \% sensitization to wheat (Bakos et al. 2006; Zuberbier et al. 2004; Mills et al. 2007; Venter et al. 2008). We found $12.5 \%$ sensitivity to rice in the study population, this is surprisingly close to a similar work from India, where $12.1 \%$ allergy patients were SPT positive to rice (Woods et al. 2002). Another report from Malaysia found $30 \%$ adult allergy patients sensitized to rice (Burks 1999). Sensitization to corn was higher in the study population (16\%) compared to the limited available international data (Orhan et al. 2009; Mills et al. 2007; Kumar et al. 2007; Obeng et al. 2011). In a clinic base study from the USA, $1.04 \%$ patients self-reported allergy to corn (Obeng et al. 2011). In another investigation on randomly selected school children in Turkish population, only $0.10 \%$ were found SPT positive for corn allergens (Orhan et al. 2009).

Forty-nine out of 689 (7.1\%) patients visiting the allergy center in this study were sensitized to banana. There is only one previous report from Egypt, where $7.5 \%$ positive SPT to banana were recorded. Data from other regions are absent. Only $9 \%$ patients from the allergy clinic were diagnosed of food allergy based on open OFC as opposed to $39.2 \%$ patients that were sensitized to one or more food allergens. This is justified because all sensitized individuals may not be symptomatic.

We report 6/689 (0.87 \%; $95 \%$ CI 0.40-1.89\%) patients in the total patient population suffering from allergy to beef. Many world-wide researchers have concluded that the prevalence of beef allergy lies between 1-10 \% (Lessof et al. 1980; Sampson and McCaskill 1985; Burks 1999; Fiocchi et al. 1995; Bock 1987; Werfel et al. 1997). 4 (0.58 \%; 95 \% CI 0.23-1.48 \%) individuals in our data population showed symptoms of milk allergy during OFC. The global prevalence of milk allergy ranges between 1-3 \% (Rance et al. 1999), whereas double-blind placebo controlled food challenge data show that milk allergy ranges between 0 and $3 \%$ (Bahna 2002). Global reports on fish allergy range from $0-7.8 \%$ in Children (Van Veen et al. 2013; Emmett et al. 1999; Werfel et al. 1997; Hochwallner et al. 2014; Soller et al. 2012; Sicherer et al. 2004; Vierk 2007; Al-Hammadi 2010; Pavlovic et al. 2014; Kajosaari 1982; Chen et al. 2012) and $0.56 \%$ in adults (Hochwallner et al. 2014). Data in the present work shows $0.73 \%$ (95\% CI 0.31-1.69) adults suffering from fish allergy. Chicken allergy from various regions around the world lies between 0-13\% (Sampson and 
McCaskill 1985; Burks 1999; Obeng et al. 2011; Laoaraya and Trakultivakorn 2012; Etesamifar 1998; Bock and Atkins 1990) whereas in our data, we calculated the prevalence of chicken meat allergy at 7(1.01\%; $95 \%$ CI 0.50-2.09\%). Egg allergy was recorded in 9/689 individuals and calculated at $1.31 \%$ (95\% CI 0.70-2.47\%). Worldwide reports estimated $31 \%$ egg allergy in infants (Palmer et al. 2013) and 0-18\% of children of all ages (Hu et al. 2010; Osborne et al. 2011; Chen et al. 2011; Van Veen et al. 2013; Werfel et al. 1997; Al-Hammadi 2010; Kajosaari 1982; Sampson and Albergo 1984; Palmer et al. 2013; Osterballe et al. 2005). Data for mutton allergy is not available, however we found in the present work, that $2 / 689$ persons did show reaction when OFC was undertaken.

No positive allergy test to soya beans and lentils was reported in this study. Allergy to soya beans in children ranges between 0-1.5 \% (Van Veen et al. 2013; Kristjansson et al. 1999; Emmett et al. 1999; Obeng et al. 2011; Venter et al. 2006; Osterballe et al. 2009) whereas in adults it is $0.03 \%$ (Vierk 2007). Lentils/legume only selfreported or clinical cross sectional data (Ostblom et al. 2008; Dalal et al. 2002; Martinez-Gimeno et al. 2000) are available but no OFC or DBPCFC reports. A case study described anaphylaxis in an 8 year old girl after ingesting lentils (Gupta et al. 2011). Such cases are rare in the population. We found $5 / 689(0.73 \%$; $95 \%$ CI $0.31-$ $1.69 \%)$ patients with peanut allergy. The prevalence of peanut allergy in school children from Montreal, Canada was $1.50 \%$ (95 \% CI 1.16-1.92\%) (Kalogeromitros et al. 1996). Researchers from different parts of the UK have reported that the prevalence of peanut allergy declines with increasing age. $1.8 \%$ prevalence was reported in 5 -year olds, $1 \%$ of 11 year olds (Kagan et al. 2003) and only $0.8 \%$ of 15 year olds (Pereira et al. 2005).

Wheat allergy was the most common as confirmed through open OFC test (1.6\%). Previously, Mehl in 2006 reported from Germany that $13.47 \%$ children aged 3 months to 14 years were suffering from wheat allergy. In Pakistan we found that only $0.87 \%$ people were suffering from rice allergy, whereas in Japanese adult atopic dermatitis patients, $2.5 \%$ were diagnosed with a rice allergy (Hourihane et al. 2007) and $3.63 \%$ patients in India were confirmed of rice allergy (Woods et al. 2002). Food challenge test results from different countries give variable prevalence to corn allergy. In the USA $0.2 \%$ (Obeng et al. 2011), UK $0.1 \%$ (Mills et al. 2007) while in Turkey it was $0 \%$ (Orhan et al. 2009). In our data corn allergy was present in $1.02 \%$ individuals. Although $0.1 \%$ ( $\mathrm{n}=969)$ banana allergy has been reported from UK (Osterballe et al. 2005), 0.9-1.2\% $(\mathrm{n}=324)$ in infants from Iceland and Sweden respectively, were diagnosed of banana allergy using food challenge tests (Van Veen et al. 2013), in the present work no banana allergy was detected.

It is concluded that among the tested group of food allergens, wheat allergy is the most prevalent in the study population. Egg allergy is the second most common type of food hypersensitivity in the group, followed by Chicken, Beef and Fish, respectively.

Results from our data along with previously reported work on food allergy, lead towards a probable hypothesis, that prevalence of sensitization to a particular kind of food depends on the frequency of consumption of that food in the study population. As we have observed here, that, wheat (most commonly eaten staple diet of Pakistan) sensitivity was the highest is our study group whereas in Japanese population rice sensitization (staple food of Japan) was reported to be the most prevalent. Conversely, it was also found that sensitization does not show any correlation to allergy symptoms, which depends on the genetic predisposition and health status of individuals and thus can not be predicted through sensitivity tests.

\section{Authors' contributions}

Study design, practical work, data collection and article compilation: MI, RHS Clinical guidance and expertise: MI and SA. Statistical analysis and interpretation: MI. Supervision, guidance and manuscript's editing/proof reading: Dr. NR. All authors read and approved the final manuscript.

\section{Author details}

1 Physiology/Endocrinology Lab, Department of Zoology, University of the Punjab, Quaid-i-Azam Campus, Lahore 54590, Pakistan. ${ }^{2}$ Department of Zoology, University of Arid Agriculture Rawalpindi (PMAS-UAAR), Rawalpindi, Pakistan. ${ }^{3}$ Allergy Asthma and Immunology Centre, Khyber Plaza Fazal-e-Haq Road, Blue Area, Islamabad, Pakistan. ${ }^{4}$ Institute of Biomedical and Genetic Engineering (IBGE), Islamabad, Pakistan.

\section{Acknowledgements}

The authors gratefully acknowledge the use of the facilities of the Institute of Biomedical Sciences and Genetic Engineering, Islamabad funded by Pakistan Science Foundation under PSF/RES/C-IBGE/Med (318).

\section{Competing interests}

The authors declare that they have no competing interests.

\section{Ethical approval}

The study was approved by Research Ethics Committee of Institute of Biomedical and Genetic Engineering (IBGE), Islamabad, Pakistan, and Advanced Studies and Research Board (ASRB) University of the Punjab Lahore, Pakistan.

\section{Originality}

It is certified that the submitted article is the original work of the authors and materials included in this article have not been used (in part/full) in any other manuscript (already submitted or in the process of publication).

Received: 28 April 2016 Accepted: 1 August 2016

Published online: 11 August 2016

\section{References}

Al-Hammadi S, Al-Maskari F, Bernsen R (2010) Prevalence of food allergy among children in Al-Ain city, United Arab Emirates. Int Arch Allergy Immunol 151(4):336-342 
Añibarro-Bausela B, Martín-Esteban M, Martínez-Alzamora F, Pascual-Marcos C, Ojeda-Casas JA (2010) Egg protein sensitization in patients with bird feather allergy. Allergy 46(8):614-618

Bahna SL (2002) Cow's milk allergy versus cow milk intolerance. Ann Allergy Asthma Imnunol 89(6 Suppl 1):56-60

Bakos N, Scholl I, Szalai K, Kundi M, Untersmayr E, Jensen-Jarolim E (2006) Risk assessment in elderly for sensitization to food and respiratory allergens. Immunol Lett 107(1):15-21

Ballmer-Weber BK, Holzhauser T, Scibilia J, Mittag D, Zisa G, Ortolani C, Oesterballe M, Poulsen LK, Vieths S, Bindslev-Jensen C (2007) Clinical characteristics of soybean allergy in Europe: a double-blind, placebo-controlled food challenge study. J Allergy Clin Immunol 119(6):1489-1496

Ben-Shoshan M, Harrington DW, Soller L, Fragapane J, Joseph L, St Pierre Y et al (2010) A population-based study on peanut, tree nut, fish, shellfish, and sesame allergy prevalence in Canada. J Allergy Clin Immunol 125(6):1327-1335

Beyer K, Teuber S (2004) The mechanism of food allergy: what do we know today? Curr Opin Allergy Clin immunol 4(3):197-199

Beyer K, Morrow E, Li XM, Bardina L, Bannon GA, Burks AW, Sampson HA (2001) Effects of cooking methods on peanut allergenicity. J Allergy Clin Immunol 107(6):1077-1081

Bock SA (1987) Prospective appraisal of complaints of adverse reactions to foods in children during the first 3 years of life. Pediatrics 79:683-688

Bock SA, Atkins FM (1990) Patterns of food hypersensitivity during sixteen years of double-blind, placebo-controlled food challenges. J Pediatr 117(4):561-567

Boyce JA, Assa'ad A, Burks AW, Jones SM, Sampson HA, Wood RA, Plaut M et al (2010) Guidelines for the Diagnosis and management of food allergy in the United States: summary of the NIAID-sponsored expert panel report. J Allergy Clin Immunol 126(6):1105-1118

Burks AW, King N, Bannon GA (1999) Modification of a major peanut allergen leads to loss of IgE binding. Int Arch Allergy Immunol 118:313-314

Caffarelli C, Cavagni G, Romanini E, Caruana P, de Angelis G (2010) Duodenal IgE-positive cells and elimination diet responsiveness in children with atopic dermatitis. Ann Allergy Asthma Immunol 86(6):665-670

Chen J, Hu Y, Allen KJ, Ho MH, Li H (2011) The prevalence of food allergy in infants in Chongqing, China. Pediatr Allergy Immunol 22(4):356-360

Chen J, Liao Y, Zhang HZ, Zhao H, Chen J, Li HQ (2012) Prevalence of food allergy in children under 2 years of age in three cities in China. ZhonghuaErKeZaZhi 50(1):5-9

Chung Y, Butts CL, Maleki SJ, Champagne ET (2003) Linking peanut allergenicity to the processes of maturation, curing, and roasting. J Agric Food Chem 51(15):4273-4277

Dalal I, Binson I, Reifen R, Amitai Z, Shohat T, Rahmani S et al (2002) Food allergy is a matter of geography after all: sesame as a major cause of severe lgE-mediated food allergic reactions among infants and young children in Israel. Allergy 57(4):362-365

Eigenann PA, Sicherer SH, Borkowski TA, Cohen BA, Sampson HA (1998) Prevalence of IgE-mediated food allergy among children with atopic dermatitis. Pediatrics 101(3):E8

Emmett SE, Angus FJ, Fry JS, Lee PN (1999) Perceived prevalence of peanut allergy in Great Britain and its association with other atopic conditions and with peanut allergy in other household members. Allergy 54(4):380-385

Etesamifar M, Wüthrich B (1998) lgE-mediated food allergies including oral allergy syndrome in 383 patients. Allergologie 21:451-457

Fiocchi A, Restani P, Riva E, Qualizza R, Bruni P, Restelli AR, Galli CL (1995) Meat allergy: i-Specific IgE to BSA and OSA in atopic, beef sensitive children. J Am Coll Nutr 14(3):239-244

Garcia BE, Lizaso MT (2011) Cross-reactivity syndromes in food allergy. J Investig Allergol Clin Immunol 21(3):162-170

Gendeh BS, Murad S, Razi AM, Abdullah N, Mohamed AS, Kadir KA (2000) Skin prick test reactivity to foods in adult Malaysians with rhinitis. Otolaryngol Head Neck 122(5):758-762

Greenhawt MJ, Singer AM, Baptist AB (2009) Food allergy and food allergy attitudes among college students. J Allergy Clin Immunol 124:323-327

Gupta RS, Springston EE, Warrier MR, Smith B, Kumar R, Pongracic J et al (2011) The prevalence, severity, and distribution of childhood food allergy in the United States. Pediatrics 128(1):e9-e17. doi:10.1542/peds.2011-0204

Haahtela T, Heiskala M, Suoniemi I (1980) Allergic disorders and immediate skin test reactivity in finnish adolescents. Allergy 35(5):433-441
Hadley C (2006) Food allergies on the rise? Determining the prevalence of food allergies, and how quickly it is increasing, is the first step in tackling the problem. EMBO Rep 7(11):1080-1083

Hefle L, Nordlee JA, Taylor SL (1996) Allergenic foods. Crit Rev Food Sci 36(Suppl):S69-S89

Heinzering L, Mari A, Bergmann KC, Bresciani M, Burbach G, Darsow U et al (2013) The skin prick test-European standards. Clin Transl Allergy 3:3. doi:10.1186/2045-7022-3-3

Hochwallner H, Schulmeister U, Swoboda I, Spitzauer S, Valenta R (2014) Cow's milk allergy: from allergens to new forms of diagnosis, therapy and prevention. Methods 66(1):22-33

Hourihane J, Aiken R, Briggs R, Gudgeon LA, Grimshaw KE, DunnGalvin A et al (2007) The impact of government advice to pregnant mothers regarding peanut avoidance on the prevalence of peanut allergy in United Kingdom children at school entry. J Allergy Clin Immunol 119:1197-1202

Hu Y, Chen J, Li H (2010) Comparison of food allergy prevalence among Chinese infants in Chongqing, 2009 versus 1999. Pediatr Int 52(5):820-824

Ito K, Urisu A (2009) Diagnosis of food allergy based on oral food challenge test. Allergol Int 58(4):467-474

Kagan RS, Joseph L, Dufresne C, Gray-Donald K, Turnbull E, Pierre YS (2003) Prevalence of peanut allergy in primary school children in Montreal, Canada. J Allergy Clin Immunol 112:1223-1228

Kajosaari M (1982) Food allergy in finnish children aged 1-6 years. Acta Paediatr Scand 71(5):815-819

Kalogeromitros D, Armenaka M, Galatas I, Capellou O, Katsarou A (1996) Anaphylaxis induced by the lentils. Ann Allergy Asthma Immunol 77(6):480-482

Katz Y, Rajuan N, Goldberg MR, Eisenberg E, Heyman E, Cohen A, Leshno M (2010) Early exposure to cow's milk protein is protective against lgEmediated cow's milk protein allergy. J Allergy Clin Immunol 126(1):77-82. doi:10.1016/j.jaci.2010.04.020 (e71)

Konstantinou GN, Asero R, Maurer M, Sabroe RA, Schmid-Grendelmeier P, Grattan CEH (2009) EAACI/GA2LEN task force consensus report: the autologous serum skin test in urticaria. Allergy 64(9):1256-1268

Krishna MT, Mavroleon G, Holgate ST (2001) Essentials of allergy. Taylor \& Francis, New York

Kristjansson I, Ardal B, Jonsson JS, Sigurdsson JA, Foldevi M, Bjorksten B (1999) Adverse reactions to food and food allergy in young children in Iceland and Sweden. Scand J Prim Health Care 17(1):30-34

Kucukosmanoglu E, Yazi D, Yesil O, Akkoc T, Gezer M, Ozdemir C et al (2008) Prevalence of immediate hypersensitivity reactions to cow's milk in infants based on skin prick test and questionnaire. Allergol Immunopathol 36:254-258

Kumar R, Srivastava P, Kumari D, Fakhr H, Sridhara S, Arora N et al (2007) Rice (Oryza sativa) allergy in rhinitis and asthma patients: a clinico-immunological study. Immunobiology 212(2):141-147

Kumar R, Kumari D, Srivastava P, Khare V, Fakhr H, Arora N, Gaur GN, Singh BP (2010) Identification of IgE-mediated food allergy and allergens in older children and adults with asthma and allergic rhinitis. Indian J Chest Dis Allied Sci 52:217-224

Kumar R, Tsai HJ, Hong X, Liu X, Wang G, Pearson C, Ortiz K, Fu M, Pongracic JA, Bauchner H, Wang X (2011) Race, ancestry, and development of foodallergen sensitization in early childhood. Pediatrics 128(4):e821-e829. doi:10.1542/peds.2011-0691

Lao-araya M, Trakultivakorn M (2012) Prevalence of food allergy among preschool children in northern Thailand. Pediatr Int 54(2):238-243

Lessof MH, Wraith DG, Merrett TG, Merrett J, Buisseret PD (1980) Food allergy and intolerance in 100 patients-local and systemic effects. Q J Med 49(195):259-271

Mackie A, Knulst A, Le TM, Bures P, Salt L, Mills EN, Malcolm P, Andreou A, Ballmer-Weber BK (2012) High fat food increases gastric residence and thus thresholds for objective symptoms in allergic patients. Mol Nutr Food Res 56(11):1708-1714

Martinez-Gimeno A, Del Castillo P, García-Hernández G, Luna-Paredes C, García-Sánchez JA, Nogales-Espert A (2000) 388 Prevalence of food allergy/intolerance in children: Results from a population based survey. J Allergy Clin Immunol 105(1):S130. doi:10.1016/ S0091-6749(00)90817-0

Mills EN, Mackie AR, Burney P, Beyer K, Frewer L, Madsen C et al (2007) The prevalence, cost and basis of food allergy across Europe. Allergy 62:717-722 
Mustafayev R, Civelek E, Orhan F, Yüksel H, Boz AB, Sekerel BE (2013) Similar prevalence, different spectrum: IgE-mediated food allergy among Turkish adolescents. Allergol Immunopathol (Madr) 41(6):387-396

Niggemann B (2010) When is an oral food challenge positive? Allergy 65(1):2-6. doi:10.1111/j.1398-9995.2009.02170.x

Novembre E, de Martino M, Vierucci A (1988) Foods and respiratory allergy. J Allergy Clin Immunol 81 (5 Pt 2):1059-1065

Obeng BB, Amoah AS, Larbi IA, Yazdanbakhsh M, van Ree R, Boakye DA (2011) Food allergy in Ghanaian schoolchildren: data on sensitization and reported food allergy. Int Arch Allergy Immunol 155(1):63-73

Orhan F, Karakas T, Cakir M, Aksoy A, Baki A, Gedik Y (2009) Prevalence of immunoglobulin E-mediated food allergy in 6-9-year-old urban school children in the eastern Black Sea region of Turkey. Clin Exp Allergy 39(7):1027-1035

Osborne NJ, Koplin JJ, Martin PE, Gurrin LC, Lowe AJ, Matheson MC et al (2011) Prevalence of challenge-proven IgE-mediated food allergy using population-based sampling and predetermined challenge criteria in infants. J Allergy Clin Immunol 127(3):668-676. doi:10.1016/j.jaci.2011.01.039 (e661-662)

Ostblom E, Egmar AC, Gardulf A, Lilja G, Wickman M (2008) The impact of food hypersensitivity reported in 9-year-old children by their parents on health-related quality of life. Allergy 63(2):211-218

Osterballe M, Hansen TK, Mortz CG, Host A, Bindslev-Jensen C (2005) The prevalence of food hypersensitivity in an unselected population of children and adults. Pediatr Allergy Immunol 16:567-573

Osterballe M, Mortz CG, Hansen TK, Andersen KE, Bindslev-Jensen C (2009) The prevalence of food hypersensitivity in young adults. Pediatr Allergy Immunol 20(7):686-692

Palmer DJ, Metcalfe J, Makrides M, Gold MS, Quinn P, West CE et al (2013) Early regular egg exposure in infants with eczema: a randomized controlled trial. J Allergy Clin Immunol 132(2):387-392

Pavlovic N, Vlahovic J, Miskulin M (2014) Prevalence of food allergies in the population of preschool children from the city of Osijek. Food Health Dis Sci Prof J Nutr Diet 3(2):78-83

Pereira B, Venter C, Grundy J, Clayton CB, Arshad SH, Dean T (2005) Prevalence of sensitization to food allergens, reported adverse reaction to foods, food avoidance, and food hypersensitivity among teenagers. J Allergy Clin Immunol 116:884-892

Prescott S, Allen KJ (2011) Food allergy: riding the second wave of the allergy epidemic. Pediatr Allergy Immunol 22(2):155-160

Rance F, Kanny G, Dutau G, Moneret-Vautrin DA (1999) Food hypersensitivity in children: clinical aspects and distribution of allergens. Pediatr Allergy Immunol 10(1):33-38

Roberts G, Lack G (2005) Diagnosing peanut allergy with skin prick and specific IgE testing. J Allergy Clin Immunol 115(6):1291-1296

Sai HPV, Anuradha B, Vijayalakshmi V, Latha SG, Murthy KJR (2006) Profile of food allergens in urticaria patients in Hyderabad. Indian J Dermatol 51(2):111-114

Sai XY, Zheng YS, Zhao JM, Hao W (2011) A cross sectional survey on the prevalence of food intolerance and its determinants in Beijing, China. Zhonghua Liu Xing Bing XueZaZhi 32:302-305

Sampson HA (2004) Update on food allergy. J Allergy Clin Immunol 113(5):805-819

Sampson HA, Albergo R (1984) Comparison of results of skin tests, RAST, and double-blind, placebo-controlled food challenges in children with atopic dermatitis. J Allergy Clin Immunol 74(1):26-33

Sampson HA, McCaskill CC (1985) Food hypersensitivity and atopic dermatitis: evaluation of 113 patients. J Pediatr 107(5):669-675
Sampson HA, Munoz-Furlong A, Bock SA, Schmitt C, Bass R, Chowdhury BA et al (2005) Symposium on the definition and management of anaphylaxis: summary report. J Allergy Clin Immunol 115(3):584-591

Schmitt DA, Maleki SJ (2003) Comparing the effects of boiling, frying and roasting on the allergenicity of peanuts. J Allergy Clin Immunol 113(2):S155. doi:10.1016/j.jaci.2003.12.566

Sicherer SH, Sampson HA (2006) Food allergy. J Allergy Clin Immunol 117(2 Suppl Mini-Primer):S470-S475. doi:10.1016/j.jaci.2005.05.048

Sicherer SH, Sampson HA (2010) Food allergy. J Allergy Clin Immunol 125(2 Suppl 2):S116-S125. doi:10.1016/j.jaci.2009.08.028

Sicherer SH, Munoz-Furlong A, Sampson HA (2003) Prevalence of peanut and tree nut allergy in the United States determined by means of a random digit dial telephone survey: a 5-year follow-up study. J Allergy Clin Immunol 112(6):1203-1207

Sicherer SH, Munoz-Furlong A, Sampson HA (2004) Prevalence of seafood allergy in the United States determined by a random telephone survey. J Allergy Clin Immunol 114(1):159-165

Soller L, Ben-Shoshan M, Harrington DW, Fragapane J, Joseph L, St Pierre Y et al (2012) Overall prevalence of self-reported food allergy in Canada. J Allergy Clin Immunol 130(4):986-988

Steckelbroeck S, Ballmer-Weber BK, Vieths S (2008) Potential, pitfalls, and prospects of food allergy diagnostics with recombinant allergens or synthetic sequential epitopes. J Allergy Clin Immunol 121(6):1323-1330

van Ree R, Poulsen LK, Wong GW, Ballmer-Weber BK, Zhongshan G, Xudong J (2015) Food allergy: definitions, prevalence, diagnosis and therapy. Chin J Prevent Med 49(1):1-17

Van Veen WJ, Dikkeschei LD, Roberts G, Brand PL (2013) Predictive value of specific lgE for clinical peanut allergy in children: relationship with eczema, asthma, and setting (primary or secondary care). Clin Transl Allergy 3:34. doi:10.1186/2045-7022-3-34

Venter C, Pereira B, Grundy J, Clayton CB, Arshad SH, Dean T (2006) Prevalence of sensitization reported and objectively assessed food hypersensitivity amongst six-year-old children: a population-based study. Pediatr Allergy Immunol 17(5):356-363

Venter C, Pereira B, Voigt K, Grundy J, Clayton CB, Higgins B et al (2008) Prevalence and cumulative incidence of food hypersensitivity in the first 3 years of life. Allergy 63(3):354-359

Vierk KA, Koehler KM, Fein SB, Street DA (2007) Prevalence of self-reported food allergy in American adults and use of food labels. J Allergy Clin Immunol 119(6):1504-1510

Waserman S, Watson W (2011) Food allergy. Allergy Asthma Clin Immunol 7(Suppl 1):S7. doi:10.1186/1710-1492-7-s1-s7

Werfel SJ, Cooke SK, Sampson HA (1997) Clinical reactivity to beef in children allergic to cow's milk. J Allergy Clin Immunol 99(3):293-300

Woods RK, Thien F, Raven J, Walters H, Abramson M (2002) Prevalence of food allergies in young adults and their relationship to asthma, nasal allergies, and eczema. Ann Allerg Asthma Immunol 88:183-189

Zuberbier T, Edenharter G, Worm M, Ehlers I, Reimann S, Hantke T, Roehr CC, Bergmann KE, Niggemann B (2004) Prevalence of adverse reactions to food in Germany-a population study. Allergy 59(3):338-345

\section{Submit your manuscript to a SpringerOpen ${ }^{\circ}$ journal and benefit from:}

- Convenient online submission

Rigorous peer review

- Immediate publication on acceptance

- Open access: articles freely available online

- High visibility within the field

- Retaining the copyright to your article

Submit your next manuscript at springeropen.com 